\title{
Personality profile of dietetics students from medical universities in the context of efficacy of prospective dietetic counseling - a Polish study
}

\author{
Michał Skrzypek ${ }^{1, A, C-F \oplus}$, Dorota Turska ${ }^{2, A, C-F \oplus}$, Lucyna Ostrowska $^{3, B-C, F}{ }^{\text {, }}$ \\ Dorota Szostak-Węgierek ${ }^{4, B-C, F \oplus}$, Renata Krzyszycha ${ }^{1, B, F}{ }^{\oplus}$, Karolina Szczygieł ${ }^{1, B, D, F \oplus}$ \\ ${ }^{1}$ Department of Clinical Dietetics, Faculty of Health Sciences, Medical University, Lublin, Poland \\ ${ }^{2}$ Institute of Psychology, Maria Curie-Skłodowska University, Lublin, Poland \\ ${ }^{3}$ Department of Dietetics and Clinical Nutrition, Medical University, Białystok, Poland \\ ${ }^{4}$ Department of Clinical Dietetics, Medical University, Warsaw, Poland \\ $A$ - Research concept and design, B - Collection and/or assembly of data, C - Data analysis and interpretation, \\ $D$ - Writing the article, $E$ - Critical revision of the article, $F$ - Final approval of article
}

\begin{abstract}
Skrzypek M, Turska D, Ostrowska L, Szostak-Węgierek D, Krzyszycha R, Szczygieł K. Personality profile of dietetics students from medical universities in the context of efficacy of prospective dietetic counseling - a Polish study. Ann Agric Environ Med. $2021 ; 28(4)$ : $639-644$. doi: $10.26444 / a a e m / 131287$
\end{abstract}

\begin{abstract}
Introduction and objective. A criterion for the efficacy of dietetic counseling is a change in patients' health behaviours. The patient-centred counseling approach in dietetics is believed to successfully induce behaviour changes. The aim of the study was to verify the assumption that students of dietetics at medical universities declare a preference for the ways of practicing dietetics which require direct work with patients, revealing a personality profile that allows implementation of the indicated approach.

Materials and method. A cross-sectional study was conducted among 427 dietetics students aged 19-31 ( $M=21.44$, $\mathrm{SD}=2.21$ ) at medical universities. Those declaring preference for the ways of practicing dietetics that entail direct contact with patients made up the criterion group. The control group was composed of students declaring preference for career paths not implying direct work with patients. The study employed Polish versions of the NEO-FFI Personality Inventory and the Schwartz Value Survey.

Results. There are four predictors of choosing career options entailing work with patients: agreeableness and conscientiousness (personality traits) and openness to change and self-transcendence (value meta-categories). When agreeableness and conscientiousness rise by 1 SD, the odds for a declared choice of working with patients increase by $151 \%$ and $139 \%$, respectively. In turn, an increase in openness to change and self-transcendence by 1 SD translates into a decline in the chances of choosing this option by $40 \%$ and $38 \%$, respectively.

Conclusions. Dietetics students at medical universities declaring a preference for direct work with patients show a personality predisposition to carefully perform professional tasks at 'technical level', and a poor predisposition to implement the patient-centred counseling approach.
\end{abstract}

\section{Iey words}

implementing behaviour change in dietetics practice, John L. Holland's congruence theory, personality profile, preferred values, dietetics students

\section{INTRODUCTION}

A criterion for the efficacy of dietetic counseling, essential from the perspective of public health, is a change in patients' health behaviours [1-2]. The question arises not only about what pattern of the dietitian-patient relationship best facilitates behaviour change, but also about what personality conditions must be met so that a particular approach can be implemented. Regarding the first question, a dietitian effective in her/his professional role builds a patient-centered relationship, in which she/he is 'a good listener, caring' [3, p.9]. The greatest potential for activating behavioural change can be found in relationships, in which the 'caring' component is most strongly manifested [3, p.30]. The National Institute for Health and Care Excellence (NICE) guidelines also highlight the importance of communication skills in behaviour change

Address for correspondence: Michał Skrzypek, Department of Clinical Dietetics, Faculty of Health Sciences, Medical University, ul. Chodźki 1, Lublin, Poland E-mail:michal.skrzypek@umlub.pl

Received: 04.11.2020; accepted: 08.12.2020; first published: 21.12.2020 interventions, emphasis being laid on skills 'to initiate conversation, develop rapport and communicate information' [4]. The European Federation of the Associations of Dietitians (EFAD) also stresses that an important educational goal in dietetics is 'the development of strong interpersonal [...] skills to enable effective communication [...]' [5, p.8]. The EFAD statement of 2016 stipulates that a dietitian must achieve competency in the domain 'communication, relationship and partnership skills in dietetics' [6, p.4]. The 'Standards of Proficiency' by the Health and Care Professions Council (HCPC) [7] also place communication competences at the core of dietetics. The common denominator of the cited theses is that dietetics tends to take into account the interpersonal determinants of behaviour change.

If we thus assume that the patient-centred counseling approach is the basic value of dietetic practice that enhances the chances of behavioural change [3-4], then it is justifiable to ask about the personality of the dietitians that enables a desirable approach to be introduced. The state of knowledge on the personality characteristics of dietitians is negligible, 
based only on very few publications [8-10], of which only one concerns the personality correlates of pursuing the specific area of professional activity [10]. Ball et al. showed in a group of Australian dietitians that, compared to the population norm, they were characterized by a high level of harm avoidance, persistence and self-directedness [9]. The authors also distinguished three personality clusters which they connected with the areas of the dietitians' practice. Personality profiles were predictors of work in two fields of occupational activity: in private practice/counseling and food service management [10]. A distinct diversity in personality traits is thus related to the areas of occupational activity situated at opposite poles of the dichotomy presenting the role of the interpersonal relationship in the dietitian's work.

The theoretical basis of this study is Holland's theory of career choice [11], according to which the choice of a particular profession is a characteristic expression of personality; the representatives of specific professions being characterized by a similar personality profile appropriate to the requirements of the work environment [12]. Holland's position offers the theoretical basis for a broad programme of the authors' research into the personality predictors of career paths declared by students of medicine [13], nursing [14] and pharmacy [15].

The studies reported in the current work focus on dietetics students. The traditional approach, used in psychological tests of representatives of medical professions, consisted in defining personality characteristics based on the Five-Factor Model (FFM) of personality: neuroticism, extraversion, agreeableness, openness to experience, and conscientiousness [16]. The authors' research programme [13-15] offers a broader understanding of personality that takes into account not only personality traits ('what people are'), but also the motivation aspect ('why people do what they do') [17]. Following the assumption that personality traits concern an individual's likely actions without taking account of his/her intentions, whereas values concern intentional goals [18], it was suggested that the Schwartz theory of basic values [19] be adopted as the representation of motivational goals. It identifies 10 value categories ('Big Ten'), which are organized along two bipolar dimensions: 'openness to change' vs. 'conservation and selftranscendence' vs. 'self-enhancement' [20].

The research approach based on the concept of personality, combining its structural aspect (FFM) with the motivation aspect ('Big Ten'), was applied in the present study, where a dichotomous division of the areas of dietitians' professional activity was adopted. Two paths of professional career in dietetics were distinguished for the purpose of this study: the first includes those forms of practicing dietetics that require direct work with patients, and the second includes other forms of practicing dietetics not requiring direct work with patients. The source of the criterion for the division is the taxonomy of medical specialties, which distinguishes 'person-oriented' and 'technique-oriented' specialties. They differ in the emphasis on the interpersonal dimension of the therapy [21].

\section{OBJECTIVES}

The study aimed to establish the personality profile of dietetics students from medical universities in the context of requirements of working with a patient within the framework of the preferred model of future career practice. On this basis, the authors verify the assumption that a specific personality constellation allows one to predict a preference for the ways of practicing dietetics, which require direct work with a patient and, at the same time, building a therapeutic relationship based on a patient-centred counseling approach. The process of career choice is studied to make some suggestions for career counselling for dietetics students from medical universities.

It was assumed that dietetics students from medical universities who declare the choice of the forms of practicing dietetics that imply direct work with a patient (within the 'clinical dietetics' formula) will show different personality characteristics, compared to respondents declaring a preference for career paths not requiring direct contact with a patient. It is expected that the personality characteristics of future clinical dietitians will enable effective implementation of the patient-centered counseling approach conducive to behavioural change. This means higher interpersonal competencies (neuroticism - lower intensity, extraversion higher intensity), higher intensity of the value meta-category of self-transcendence', which will be conducive to achieving behavioural change at a lower intensity of agreeableness.

\section{MATERIALS AND METHOD}

Sample and procedure. The survey was conducted between December 2017 - June 2019 among 427 students (aged 1831 years, $\mathrm{M}=21.44, \mathrm{SD}=2.21), 372$ females $(87 \%)$, attending first- and second-cycle degree programmes in dietetics at three purposively selected Polish medical universities in Lublin, Warsaw, and Białystok, who expressed written informed consent. Due to the fact that dietetics programs are also offered in Poland by non-medical universities, the authors of the study do not aspire to satisfy the requirement that the studied sample is representatives of the whole population of dietetics students in Poland. On the other hand, the method of selecting the research sample enables meeting the adopted research objective, i.e. to establish the personality profile of dietetics students attending medical universities in the context of the psychological requirements of building a therapeutic relationship with a patient. The dietetics profession, especially if practiced within the clinical dietetics formula, consists in direct work of the dietitian with a patient as part of a therapeutic team headed by a doctor. This makes it necessary for those practicing this profession to have appropriate professional qualifications and, as in the case of other medical professions, to have interpersonal competencies that enable building a therapeutic relationship with a patient.

The surveyed sample consisted of 287 (67\%) students attending the first-cycle programme in dietetics, culminating in a Bachelor's degree, and 140 (33\%) students attending the second-cycle programme culminating in a Master's degree. Participation in the survey was voluntary and anonymous. In total, 390 students $(91.3 \%$ of all the respondents) fully completed the questionnaires. Only this data was analyzed. Thus, the analyzed sample consisted of 390 students (aged $19-31$ years, $\mathrm{M}=21.57, \mathrm{SD}=1.92$ ), including 342 females (87.7\%). In the analyzed sample, $260(66.7 \%)$ students attended the first-cycle programme in dietetics, culminating in a Bachelor's degree, and 130 (33.3\%) students 
attended the second-cycle programme culminating in a Master's Degree.

Measures. A cross-sectional survey research method was used to describe the personality predictors of the choice of career path by dietetics students and preferences for the forms of practicing dietetics that require direct work with a patient and building a therapeutic relationship. Validated surveys were used.

The Polish version of the NEO Five-Factor Inventory (NEO-FFI) by Costa and McCrae was used to measure the personality traits [22]. The questionnaire contains 60 statements representing the five factors: neuroticism (prone to feeling anxious, and difficulty in coping with stress induced by contacts with people), extraversion (the number and quality of social interactions), agreeableness (trust towards people, but also compliance and an inclination to yield), openness to experience (a preference for new ideas), and conscientiousness (the degree of an individual's good organization, his/her sense of responsibility) [16]. Each scale consists of 12 items assessed on a five-degree scale from 1 ('definitely do not agree') to 5 ('definitely agree'). The reliability coefficients, estimated on the basis of Cronbach's alpha internal consistency coefficient, are: from 0.82 for the 'conscientiousness' scale to 0.68 for 'openness to experience' and 'agreeableness' [22].

To measure value preferences, the Schwartz Value Survey (Polish adaptation) [23] was used, in which 10 basic values were distinguished and organized along two bipolar dimensions. The first - the meta-categories of 'openness to change' vs. 'conservation' - is composed of opposing values: from those emphasizing independence of thought and readiness for change (self-direction, stimulation) to values emphasizing stability (conformity, tradition, security). The other dimension, consisting of the meta-categories of 'self-transcendence' vs. 'self-enhancement', in turn is made up of values emphasizing others as equals and concern for their welfare (benevolence, universalism), contrasted with values that emphasize the pursuit of one's own interests and dominance over others (achievement, power) [20]. The respondent rates the degree to which each value item is a guiding principle in his/her life. The values are rated on a 9-point scale from -1 ('opposed to my values') to 0 ('unimportant') to 7 ('of supreme importance'). Cronbach's alpha reliability coefficients on the scale are from 0.53 ('hedonism') - 0.78 ('benevolence') [23].

The authors' survey was used concerning the respondents' socio-demographic characteristics and preferred career path. They were asked to indicate one of the options: outpatient dietetic counseling centre; outpatient medical clinic; hospital ward; nursing home/hospice/sanatorium; kindergarten, school; sports/fitness club; resort/SPA (direct work with patients/clients); education institution; university, college (teaching); catering; hospital/sanatorium/nursing home nutrition department (nutrition planning); media; research institution; sanitary-epidemiological station; food processing company; company manufacturing/selling/testing dietary supplements; company dealing with HACCP; food testing laboratory. The list of self-declared options corresponds to employment opportunities for dietitians in Poland. In the reported studies, the dependent (explained) variable was 'an occupational preference', i.e. the occupation/career path 'which at a given time, an individual would like or prefer to enter' [24].
All the participants were subject to the same research procedure, i.e. the NEO-FFI, followed by the Schwartz Value Inventory, and finally the declaration concerning the preferred career path in dietetics.

All data related to this research is available online through Mendeley Data repository [25].

The study protocol was approved by the Medical University of Lublin Bioethics Committee (Resolution No. KE-0254/289/2017). The approved and implemented study protocol provided for the cross-sectional assessment of the personality profile of dietetics students from purposively selected medical universities in the context of the career path declared/preferred by students at a specific stage of preparation for the dietetics profession (university training).

Statistical procedure and analysis. Statistical analysis was carried out using the Statistical Package for Social Sciences (SPSS) version 25. In order to verify the research hypothesis, a multivariate analysis of logistic regression was conducted.

\section{RESULTS}

The students mostly indicated practice at an outpatient dietetic counseling centre as the preferred career path $(n=152$; $39 \%)$. The other very frequently indicated career options were: working at an outpatient medical clinic $(n=60 ; 15.4 \%)$, in a hospital ward $(n=37 ; 9.5 \%)$ and at a sports/fitness club $(n=35$; 9\%). The students who selected career options entailing the work with patients/clients, formed the criterion group $(n=301$, females $-89 \% ; 77.2 \%$ of respondents). The other respondents declared a preference for the career paths that do not imply direct work with patients/clients. These respondents formed the control group $(n=89$, females $-88 \%$; a total of $22.8 \%$ of respondents who fully completed the survey). The most often indicated career options in the control group were: employment in the media ( $\mathrm{n}=24 ; 6.2 \%$ of indicated options), in a nutrition research institution $(n=13 ; 3.3 \%)$ or in a laboratory $(n=12 ; 3.1 \%)$.

Despite the unequal number of respondents in the criterion and control groups, it was decided to conduct comparative analyses for two reasons. First, the compared groups exhibited the homogeneity of variances of all the analyzed variables (statistically insignificant results of Levene's test). Second, in the criterion and control group there were equal proportions between men and women (insignificant value of the Z-test). Since the diversity in personality traits in terms of gender was demonstrated [22], the potential and factual influence of gender on the results of comparative analyses was thereby eliminated.

In the logistic regression, the following way of coding the declaration of the choice of career path (dependent value) was adopted: preference for working with patients/clients $=1$, other options $=0$. In addition to the personality traits, only the meta-categories of the values were introduced into the model. Such an approach was prompted by the need to maintain the relation between the size of the sample and the number of independent variables [26], and by conviction that the meta-categories of the values are more efficacious to predicting behaviour [27] (Tab. 1).

On the basis of the results (Tab.1), there are four personality predictors for the choice of the form of practicing dietetics 
Table 1. Model of logistic regression explaining declared choice of career path - working with patients

\begin{tabular}{|c|c|c|c|c|c|c|}
\hline predictors & B & Wald (Z) & $\mathrm{p}$ & OR & 95\% confidence interval OR & OR for change by $1 \mathrm{SD}^{*}$ \\
\hline neuroticism $^{* *}$ & 0.03 & 2.76 & 0.10 & & & \\
\hline extraversion & 0.01 & 0.19 & 0.66 & & & \\
\hline openness to experience & 0.03 & 0.83 & 0.36 & & & \\
\hline agreeableness & 0.06 & 7.88 & 0.01 & 1.06 & $1.02-1.11$ & 1.51 \\
\hline conscientiousness & 0.046 & 5.62 & 0.05 & 1.05 & $1.00-1.08$ & 1.39 \\
\hline CONSERVATION & 0.36 & 3.17 & 0.75 & & & \\
\hline OPENNESS TO CHANGE & -0.53 & 6.88 & 0.01 & 0.59 & $0.39-0.88$ & 0.60 \\
\hline SELF-TRANSCENDENCE & -0.58 & 4.97 & 0.05 & 0.56 & $0.33-0.93$ & 0.62 \\
\hline
\end{tabular}

"calculation as per formula: $\mathrm{OR}(\mathrm{SD})=\exp (\mathrm{BxSD}) ;{ }^{* *}$ names typed in small print denote personality traits; ${ }^{* * *}$ names in capitals denote meta-categories of values after the Schwartz theory.

classified as 'working with a patient': 'agreeableness' and 'conscientiousness' (personality traits, positive predictors), and 'openness to change' and 'self-transcendence' (metacategories of values, negative predictors).

The analysis of OR as a measure of effect indicates that where the value of a given predictor increases, the odds for choosing work with patients increase with respect to the personality traits 'agreeableness' and 'conscientiousness'. As regards the meta-categories of the values 'openness to change' and 'self-transcendence', the opposite is the case: a rise in the value of explanatory variables translates into a decrease in the odds for choosing work with patients. Taking into account the fact that the independent variables introduced into the model are quantitative in nature, the OR for a singular change may not visibly reflect the analyzed effect. A rise in the value of such a variable by one unit is of little significance. Therefore, the OR for any change in the value of the predictor was calculated [28].

The data presented in the last column in Table 1 inform that where 'agreeableness' and 'conscientiousness' rise by 1 SD, the odds for a declared choice of working with patients increase by $151 \%\left\{\{1.51-1)^{\star} 100\right\}$ and $\left.139 \%\{1.39-1)^{\star} 100\right\}$, respectively. In turn, an increase in the value of the meta-categories 'openness to change' and 'self-transcendence' by 1 SD translates into a decline in the chances of choosing work with patients by $40 \%\left\{(1-0.60)^{\star} 100\right\}$ and $38 \%\left\{(1-0.62)^{\star} 100\right\}$, respectively.

The tested model proved to be well calibrated, as confirmed by the Hosmer-Lemeshow test for goodness of fit $\left(\mathrm{chi}^{2}=13.26\right.$; $\mathrm{df}=8 ; \mathrm{p}=0.10)$. This procedure allows correct classification of $98 \%$ of students who declared the choice of 'work with patients'.

\section{DISCUSSION}

The current study provides data on the poorly researched question of the personality profile of dietetics students from medical universities, and their predispositions to implement a patient-centred relationship in dietetics. This approach enhances the chances of behavioural change and thus the effectiveness of dietetic counseling, and of achieving the goals of public health [3-4].

The hypothesis suggested that graduates from medical universities showing preference for working with patients/ clients would display personality characteristics appropriate for the functional requirements of practice in this area. This means the presence of personality predispositions that are conducive to building a patient-centred relationship. As part of this relationship, it is important to be able to initiate behaviour change in accordance with medical guidelines. For that reason, a special intensity of traits was expected, which are the 'tools' of efficient interpersonal communication: relatively higher extraversion and lower neuroticism, since extraversion facilitates entering into relationships with people, whereas low neuroticism helps to more effectively cope with stress resulting from social contacts. Above all, however, predominance was expected in the value meta-category of self-transcendence as being widely oriented towards the welfare of others. It is only high self-transcendence that offers the deepened 'quality' of interpersonal relationships: empathy for him/her and unconditional acceptance. The effectiveness of the therapeutic relationship, on the other hand, was operationalized through a lower intensity of agreeableness.

The obtained results did not confirm the formulated hypothesis. The students who declared preference for working with patients, in comparison with the control group, were not found to be less neurotic and more extrovert. Results differing from those expected were also obtained: the respondents from the criterion group were characterized by relatively higher agreeableness and showed a lower level of preference for the value meta-category 'self-transcendence'. Furthermore, two unexpected predictors for the choice of work with patients were revealed: the personality trait conscientiousness (positive predictor) and the value metacategory of 'openness to change' (negative predictor).

Agreeableness is associated with stronger confidence in people, but first of all it denotes general submissiveness in interpersonal relationships - compliance and a tendency to yield to others, as well as little independence of thought and action. In the context of the requirements of the dietitian's work focused on producing change in nutrition behaviours, it should be concluded that greater agreeableness will not be conducive to achieving the defined dietetic intervention goals. Moreover, the personality tendency of dietetics students to preserve the existing solutions may be conducive to the ossification of the current framework of practicing the dietetic profession in Poland, and to restraining new legal solutions (regulation of the profession) that require reorganizing a number of aspects in the current functioning of professional dietitians (supervision and verification of qualifications held, the duty of continuing education etc.). The completion of work in Poland on the legal regulation of rules governing access to the dietetics profession, taking account of the standardization of training in dietetics, would 
enable devising and implementing in practice education programmes entailing obligatory training in interpersonal competencies.

The presented study should provide preliminary empirical grounds for formulating appropriate recommendations. These are interpersonal skills workshops. Their training content should entail both the development of skills of interpersonal communication with and support for the patient, and enhancing the assertiveness of future dietitians.

Higher conscientiousness, in turn, implies a sense of responsibility, discipline, and a high level of requirements towards oneself. This trait seems to predispose one well to evidence-based dietetics practice that entails implementing medical nutrition guidelines. Combined with the trait 'conscientiousness', the predisposition to postponing quick gratification for more distant goals may have an adaptive value in the case of dietetic interventions as part of the prevention and treatment of chronic diseases. Care and meticulousness at work also seems to have an adaptive value in the context of the dietitian's work consisting, among others, in planning menus in line with clinical requirements.

The meta-category of 'transcendence', contrary to the expectations, turned out to be a negative predictor for the choice of a career path entailing direct work with a patient. This means that the axiological preferences of the respondents in the criterion group did not focus on building a universalist relationship of helping that would encompass all those seeking help who are not connected with the helper by family ties or friendship. The constituent elements of this value meta-category are: benevolence, i.e. concern for the welfare of close family and friends (the 'in-group' [19]), as well as universalism involving the transfer of this tendency onto the whole of society; this detailed value also includes concern 'for the welfare of all people' [19].

Dietetics students from medical universities who chose work with a patient exhibited a low independence of thought and action, in combination with low scores in the meta-category of 'openness to change' (an unexpected negative predictor). The constituents of openness to change are self-direction ('independent thought and action') [19], and stimulation ('novelty, and challenge in life') [19]. The preference for the two values was low in the criterion group. The presented axiological preference will be conducive to meticulous implementation of the medical guidelines in dietetic practice and will predispose one to working in a therapeutic team based on subordination to the decisions of the team leader (physician). However, the expected submissiveness of dietetics graduates from medical universities will not, it appears, be conducive to emphasizing the professional position of dietitian in a therapeutic team, or to building the dietitian's strong position in the medical system.

When commenting on the results, it is necessary to refer to the unequal numbers in the control and criterion group. This result reflects the actual distribution of preferences concerning the professional career path of dietitians. The presented study was conducted at selected medical universities that train students to practice this profession first and foremost within the EFAD scope of clinical dietetics [5-6]. This may have had an impact on the declarations of students, who, already when choosing a medical university, may have assumed that they would be trained to practice the chosen profession working with patients. Declarations on the professional career path amongst dietetics students trained at non-medical universities may be different, as may also be the personality profile of dietetics students from nonmedical universities. Consequently, since the study focuses only on dietetics students from selected medical universities, it cannot be generalized to cover the personality profile and career choices among the community of dietetics students in general.

Strengths and Limitations of the Study. To the best of the knowledge of the authors, this is the first Polish and European study on the personality profile of dietetics students from medical universities, and personality predictors of a preferred career path in dietetics.

The adopted dichotomy of the ways of practicing dietetics does not take account of the internal diversity within the two opposing areas of dietitians' professional activity. For example, work with a patient can be conducted as an outpatient practice, which implies a low level of peer support, or conducted as hospital medical care. These two areas of activity, both entailing direct work with patients, thus imply other personality predispositions where the former requires greater self-directedness, as well as resistance to risk and uncertainty [10].

The study was cross-sectional and provides no grounds for inferring that there is a cause-and-effect relationship between the exposure (personality traits and preferred values) and the outcome (preference for the ways of practicing dietetics, which requires direct contact with patients).

Recruitment of the research sample from students on dietetics programmess taught at medical universities excluded the formulation of generalized conclusions concerning the whole population of dietetics students in Poland. It was not the intention of the authors to formulate such conclusions.

The study assessed the choice preferences for a career in dietetics at a specific point of time, rather than the actual choice of the way of practicing this profession. However, by referring to the classic concept of career development [29], it could be assumed that the studied students reached the stage of crystallization of their career goal. Consequently, it can be justifiably expected that they are determined to pursue a specific form of career and will reject the remaining options.

\section{CONCLUSIONS}

Dietetics students from medical universities in Poland are characterized by a personality predisposition to carefully perform their professional tasks at their 'technical' or instrumental level, with a simultaneous 'weak' competence to establish a patient-centred counseling approach, as shown in Fellers' study [30]. There are therefore no grounds for supposing that they will be able to effectively initiate change in patients' health behaviours. The areas of practicing dietetics that entail direct work with patients and are part of clinical dietetics require that the training curricula in medical universities should activate the competencies necessary to build a patient-centred counseling approach conducive to behavioural change in dietetics practice. The format that should be pointed to here is the workshops of interpersonal skills, of strategies for supporting patients, and of developing assertiveness in dietitians.

The authors treat the present study as a step towards more complete professionalization of the profession of dietitian 
in Poland, whose desirable element is deliberate conscious choices of career development, consistent with personality predispositions.

\section{REFERENCES}

1. who.int [Internet]. World Health Organization. Preventing chronic diseases: a vital investment: WHO global report; [cited 2020 May 10]. Available from: https://www.who.int/chp/chronic_disease_report/en/.

2. Syme SL. The prevention of disease and promotion of health: the need for a new approach. Eur J Public Health. 2007; 17(4): 329-330. https:// doi.org/10.1093/eurpub/ckm081

3. Gable J, Herrmann T. Counselling skills for dietitians. Oxford: Blackwell Publishing; 2007.

4. nice.org [Internet]. National Institute for Health and Care Excellence. Behaviour change: individual approaches; [cited 2020 Jan 10]. Available from: https://www.nice.org.uk/Guidance/PH49.

5. efad.org [Internet]. European Federation of Associations of Dietitians European Academic and Practitioner Standards for Dietetics; [cited 2020 Jan 10]. Available from: http://www.efad.org/media/1442/efad benchmarkjune2005_uk.pdf.

6. efad.org [Internet]. European Federation of Associations of Dietitian. Dietitians in Europe. Definition, Profession and Education. Statement by the EFAD; [cited 2020 Jan 10]. Available from: http://www.efad.org/ media/1128/revised-definition-of-a-dietitian.pdf.

7. hcpc-uk.org [Internet]. Health \& Care Professions Council. Standards of proficiency. Dietitians; [cited 2020 Jan 10]. Available from: https:// www.hcpc-uk.org/resources/standards/.

8. Hagan DW, Taylor AD. The personality of dietetics. J Am Diet Assoc. 1999; 99(6): 667-668. https://doi.org/10.1016/S0002-8223(99)00397-1

9. Ball L, Eley DS, Desbrow B, et al. A cross-sectional exploration of the personality traits of dietitians. J Hum Nutr Diet. 2015; 28(5): 502-509. https://doi.org/10.1111/jhn.12265

10. Ball L, Eley DS, Desbrow B, et al. Association between dietitians' personality profiles and practice areas. Nutr Diet. 2016; 73(3): 247-253. https://doi.org/10.1111/1747-0080.12222

11. Holland JL. Making vocational choices. Odessa: Psychological Assessment Resources Inc; 1997.

12. Soto JA. Personality-career fit and freshman medical career aspirations: a test of Holland's theory. Res High Educ.1998; 39: 679-698.

13. Turska D, Skrzypek M, Tychmanowicz A, et al. Concept of distinct surgical personality revisited. Am J Med Technol. 2016; 1: 38-46.
14. Turska D, Skrzypek M, Wrońska I, et al. Personality predictors of surgical specialties choice among students of nursing. Curr Iss Personal Psychol. 2017; 5(2): 123-131. https://doi.org/10.5114/cipp.2017.65204

15. Skrzypek M, Turska D, Marzec A, et al. Personality traits and personal values as retail pharmacy choice predictors in the context of pharmaceutical care requirements. Res Social Adm Pharm. 2020; 16(1): 68-73. https://doi.org/10.1016/j.sapharm.2019.03.001

16. Costa PT, McCrae RR. Revised NEO Personality Inventory and NEO Five-Factor Inventory. Odessa: Psychological Assessment Resources Inc; 1992.

17. Epstein S. Trait theory as personality theory. Psychol Inq. 1994; 2: 120-122.

18. Bilsky W, Schwartz SH. Values and personality. Eur J Pers. 1994; 8: 163-181.

19. Schwartz SH. An overview of the Schwartz theory of basic values. ORPC. 2012: 2(1): 1-20. https://doi.org/10.9707/2307-0919.1116

20. Cieciuch J. [The formation of the value system. From childhood to early adulthood]. Warszawa: Liberi Libri; 2013. In Polish.

21. Manuel RS, Borges NJ, Jones BJ. Person-oriented versus techniqueoriented specialties: early preferences and eventual choice. Med Educ Online. 2009; 14(4): 1-6. https://doi.org/10.3885/meo.2009.Res00284

22. Zawadzki B, Strelau J, Szczepaniak P, et al. [Personality Inventory NEO-FFI Costa \&McCrae. Polish adaptation]. Warszawa: PTP; 1998. In Polish.

23. Brzozowski P. [Model hierarchy of values]. Lublin: UMCS; 2007. In Polish.

24. Matteson MT, Smith SV. Selection of medical specialties: preferences versus choices. J Med Educ. 1977; 52: 548-554. https://doi. org/10.1097/00001888-197707000-00002

25. Skrzypek M, Turska D, Szostak-Węgierek D, Ostrowska L, Krzyszycha R, Szczygieł K. Dietetics students declaring a preference for direct work with patients show a poor personality predisposition to use the patientcentered counseling approach [dataset]. 2020 Apr 16 [cited 2020 Apr 16]. Mendeley Data Database. Available from: https://data.mendeley. com/datasets/d4yd7trhnx/1. Referenced in doi: 10.17632/d4yd7trhnx.1

26. Danieluk B. [Application of logistic regression in experimental research]. Psychol Społ. 2010; 5: 199-216. In Polish.

27. Schwartz SH, Boehnke K. Evaluating the structure of human values with confirmatory factor analysis. J Res Pers. 2004; 38: 230-255. https:// doi.org/10.1016/S0092-6566(03)00069-2

28. Hosmer DW, Lemeshow S. Applied logistic regression. New York: John Wiley\&Sons INC; 2000.

29. Tiedeman OV, O'Hara RP. Career development: choice and adjustment. New York: College Entrance Examination Board; 1963.

30. Fellers RB. Relationships between career satisfaction and personality type for employed dietitians. Gainesville: University of Florida; 1974. 